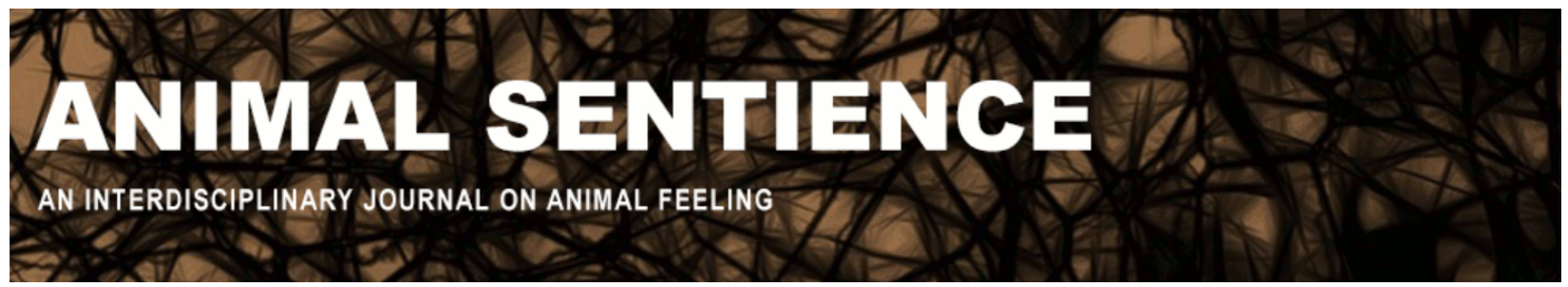

Brown, Rachael L. (2017) Not statistically significant, but still scientific. Animal Sentience 16(14)

DOI: $10.51291 / 2377-7478.1247$

Date of submission: 2017-11-09

Date of acceptance: 2017-11-13

(c)

This article has appeared in the journal Animal

Sentience, a peer-reviewed journal on animal

cognition and feeling. It has been made open access,

free for all, by WellBeing International and deposited

in the WBI Studies Repository. For more information,

please contact

wbisr-info@wellbeingintl.org.

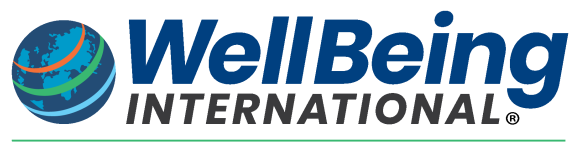

SOLUTIONS FOR PEOPLE, ANIMALS AND ENVIRONMENT 


\title{
Not statistically significant, but still scientific
}

\author{
Commentary on Birch on Precautionary Principle
}

\author{
Rachael L. Brown \\ School of Philosophy \\ College of Arts and Social Sciences \\ Australian National University
}

\begin{abstract}
Birch's formulation is persuasive but not nuanced enough to capture at least one situation where it is reasonable to invoke the precautionary principle (PP): when we have multiple, weak, but convergent, lines of evidence that a species is sentient, but no statistically significant evidence of a single credible indicator of sentience within the order as required by BAR. I respond to the worry that if we include such cases in our framework for applying the PP, we open ourselves to the charge of being "unscientific."
\end{abstract}

\begin{abstract}
Rachael L. Brown, Director of the Centre for Philosophy of the Sciences, Australian National University, works on the evolution of cognition and behaviour; the relationship between evo-devo and the Neo-Darwinian Synthesis; model-based reasoning in biology and philosophy; and methodological issues in the study of animal behaviour and cognition.

www.rachaelbrown.net
\end{abstract}

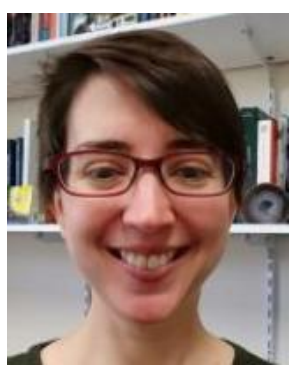

Birch (2017) presents us with a "first-pass" framework for applying the Precautionary Principle (PP) to the question of animal sentience. I am broadly sympathetic to Birch's approach but worry that the emphasis on "statistically significant evidence" of at least one credible indicator of sentience is too strong. It fails to take into account the type of evidence that we frequently have available to us in the case of animal sentience research.

As noted by Birch, credible and meaningful application of the PP to the question of animal sentience involves (among other things) balancing our concern for animal welfare with our concern for having scientifically respectable welfare policy. For scientific credibility, Birch leans heavily on "normal scientific standards"; for our concerns about risk of harm, he requires one credible indicator of sentience in at least one species of the order. Birch's decision to require statistically significant scientific evidence of just one credible indicator of sentience may seem quite generous, but BAR is actually too strong for some situations where one might 
reasonably want to invoke the PP: cases where we have multiple, weak, but convergent, lines of evidence that a species is sentient, but no statistically significant evidence of a single credible indicator of sentience within the order.

Such a situation is not just a hypothetical possibility. Evidence for sentience in animals is often weak because of the practical challenges of studying animal cognition, as well as the opaque nature of sentience itself. In looking for signs of sentience in other species, our evidence is frequently undermined by:

A reliance on small sample sizes: This is commonly the product of small, captive populations or the challenges that temperament and life history can pose to the study of wild individuals.

The use of highly enculturated or habituated subjects: This is typically a result of reliance on small, frequently studied captive populations, but it can also be due to the prior training of subjects that some tests for sentience require.

Reliance on anecdotal or observational report: Such reports are typically seen as lacking scientific rigor. Despite this, we often have far more of this type of evidence than we have from controlled laboratory studies (see Browning's (2017) commentary on this article for a more detailed discussion).

The phylogenetic distance between the target species and our own or other species widely accepted to be sentient: This distance weakens the strength of inferences based on homology and is most troublesome when we are dealing with non-mammalian species. (The detailed recent discussion on sentience and the neurophysiology of fish in this journal (Key 2016; Woodruff 2017) offers a good illustration of the challenge posed by phylogenetic distance.)

The challenges posed by producing a species-specific behavioural test for sentience: "Gold standard" tests such as the self-delivery of analgesics have physiological, cognitive and behavioural requirements that need to be adjusted to suit the particular species in question. Such adjustments are not always feasible.

It is always possible that the reason we have limited, poor-quality evidence for the sentience of a species is that it is not actually sentient, but not all cases of limited or poor-quality evidence are the same. There is a big difference between having (1) many lines of weak, but convergent, positive evidence for sentience, and having (2) a little weak positive evidence along with many lines of negative evidence, or (3) many lines of weak evidence in which there is no particular trend for or against sentience. In (1) (but clearly not (2) and (3)), although we lack statistically significant evidence, we do have some empirical justification for invoking something like the PP on the grounds of inference to the best explanation (IBE). Indeed, this looks like exactly the situation in which advocates of the PP would want to invoke the principle-to allow action where we have good justification for thinking a species may be sentient, but not enough for statistical significance on even one credible indicator of sentience. 
This proposed change to BAR does not necessarily put the scientific credibility of the PP at risk. To invoke IBE across multiple lines of weak, but convergent, evidence is not to invite insensitivity to evidence: it is to take seriously precisely the kind precaution against inaction in the face of evidence for sentience that the PP was originally formulated to achieve. Moreover (as Birch notes), far from being "unscientific," IBE is a common form of reasoning in science. Birch himself uses IBE in his formulation of the PP. All I add is the suggestion to extend the PP across different credible indicators to include not only statistically significant evidence of sentience, but also multiple, weak and convergent evidence. This is in line with the original motivations behind the PP.

Acknowledgements: Many thanks to Heather Browning and Jessica Isserow for their thoughts on this.

\section{References}

Birch, J. (2017) Animal sentience and the precautionary principle. Animal sentience 16(1)

Browning, H. (2017) Anecdotes can be evidence too. Animal Sentience 16(13)

Key, B. (2016) Why fish do not feel pain. Animal Sentience 3(1)

Woodruff, M. L. (2017) Consciousness in teleosts: There is something it feels like to be a fish. Animal Sentience 13(1) 


\section{ANIMAL CONSCIOUSNESS}

On November 17-18, 2017, the NYU Center for Mind, Brain and Consciousness, the NYU Center for Bioethics, and NYU Animal Studies will host a conference on Animal Consciousness.

This conference will bring together philosophers and scientists to discuss questions such as: Are invertebrates conscious? Do fish feel pain? Are nonhuman mammals self-conscious? How did consciousness evolve? How does research on animal consciousness affect the ethical treatment of animals? What is the impact of issues about animal consciousness on theories of consciousness and vice versa? What are the best methods for assessing consciousness in nonhuman animals?

\section{Speakers and panelists include:}

Colin Allen (University of Pittsburgh, Department of History \& Philosophy of Science), Andrew Barron (Macquarie, Cognitive Neuroethology), Victoria Braithwaite (Penn State, Biology), Peter Carruthers (Maryland, Philosophy), Marian Dawkins (Oxford, Zoology), Dan Dennett (Tufts, Philosophy), David Edelman (San Diego, Neuroscience),

Todd Feinberg (Mt. Sinai, Neurology), Peter Godfey-Smith (Sydney, Philosophy), Lori Gruen (Wesleyan, Philosophy), Brian Hare (Duke, Evolutionary Anthropology), Stevan Harnad (Montreal, Cognitive Science), Eva Jablonka (Tel Aviv, Cohn Institute), Björn Merker (Neuroscience), Diana Reiss (Hunter,

Psychology), Peter Singer (Princeton, Philosophy), Michael Tye (Texas, Philosophy)

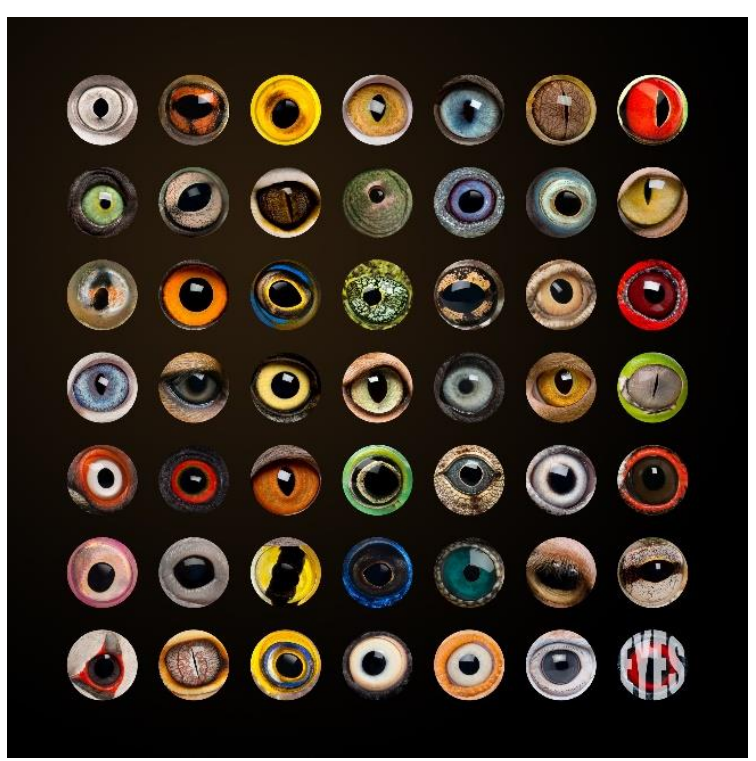

Organizers: Ned Block, David Chalmers, Dale Jamieson, S. Matthew Liao.

The conference will run from 9am on Friday November 17 to $6 \mathrm{pm}$ on Saturday November 18 at the NYU Cantor Film Center (36 E 8th St).

Friday sessions will include "Invertebrates and the evolution of consciousness", "Do fish feel pain?", and "Animal consciousness and ethics".

Saturday sessions will include "Animal self-consciousness", "Animal consciousness and theories of consciousness", and a panel discussion.

A detailed schedule will be circulated closer to the conference date.

Registration is free but required.

\section{Register here.}

\section{See also the conference website}

